The interest of this study depends on the use of a statistical method (main component analysis) by means of which it was possible to show the influence of the principal environmental factors on the performances of fattening pigs.

The results of $4^{16}$ batches of pigs obtained in 91 pig houses of 6 different types were analysed and showed the favourable influence of air volume per pig, thus demonstrating the necessity of using lofty rooms.

The effect of the region was very important. This effect includes clifferent factors : origin of the piglets, climate, feed, which renders the interpretation more difficult.

We hope that further studies using an analogous method of interpretation will complete these informations and provide a more accurate definition of the environmental conditions satisfying the requirements of fattening pigs.

\title{
Fattening performances of Large White pigs in difierent piggeries according to the season and choice of cereals
}

\author{
B. DESMOULIN
}

Station de Recherches sur l'İlevage des Porcs, I. N. R. A., C. N. R. Z., 78350 Jouy en Josas

Two diets, barley-soyabean or maize-soyabean, containing $53 \mathrm{~g}$ digestible crude protein and $2.5 \mathrm{~g}$ lysine for $\mathrm{I}$ ooo $\mathrm{kcal}$ digestible energy were offered simultaneously in three different pig houses during three successive seasonal replications. The effects of type of housing, feeding systems (individual or in groups with or without individual feeding troughs) and alternation of cold and hot seasons were studied in 2 I 6 Large White pigs. The results concern the environmental factors of the production system :

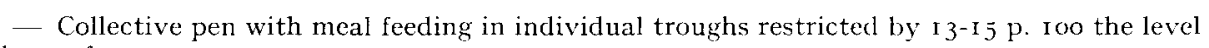
of the performances.

- Seasonal fluctuations partly controlled by heating and (or) ventilation of the piggeries did not directly affect the performances. On an average these performances were equivalent with diets based on barley or maize, taking into account the different energy values.

However, in the case of separate feeding of castrated males and females, the utilization of cereals was not equivalent for both sexes in the different production systems.

A) The maize-soyabean diet was generally better used for growth in the castrates the feed conversion ratio $\left(3.5^{8}\right)$ of which was similar to that of the females $(3.45)$. On the other hand the barley-soyabean diet was better used by the females, the growth of which started in the hot season ; in that case, feed conversion ratios were equivalent in females fed with barley (3.25) or maizc (3.27). The risks of feed intake reduction depending on environmental factors (housing conditionsseason) were less marked in the females, better adapted to feed restrictions.

B) The excessive fatness of the carcasses of castrates was almost equivalent in all seasons ; the loin/backfat ratio was $23 \mathrm{p}$. Ioo higher in the females. For the latter, fatness was reduced when growth started in the hot season. Conversely, winter-summer growth led to a definitive pre-fattening of the females. At slaughter, backfat weight $(6.07 \mathrm{~kg})$ was comparable to that of the castrates 
$\left(6.4^{8} \mathrm{~kg}\right)$. Thus, the risks of feed intake increase depending on seasonal infuences penalized more the females, not restricted during early growth.

For production in batches of separated sexes (DEsmoulin, I969-197I), seasonal feed restrictions can be accompanied by a preferential choice of cereals : maize in the castrates, barley in the females.

\title{
Survey on the monitoring of an aeration processed waste disposal unit treating a mixture of swine and cattle manure
}

\author{
J. SENNELIER, P. POULET, J.-P. RAYNAUD \\ Station de $R$ et $D$. Vétérinaive et Nutrition animale, \\ Pfizer International, B.P. 42, \\ 37400 Amboise \\ Biologie appliquée, Option Hygiène de l'Environnement, \\ Institut Universitaire de Technologie, \\ 37000 Tours
}

We are presenting the results of the handling of a waste disposal unit (aeration process) treating a mixture of swine and cattle waste. This study was undertaken to obtain an acceptable effluent and to improve the efficiency of this unit. It was demonstrated that the following measures hac to be followed for a good processing :

I) Screening to retain non biodegradable crude fibres (important if dairy cattle). It is not necessary to use too fine a screen as we found that there was practically non difference between a 4 oo and 600 screen.

2) Sufficient quantity of water to obtain a diluted manure. In this unit, we found that the decantation was disturbed when over $9 \mathrm{~g} / 1$ of total suspended solids were present in the oxidation tanks. With a maximum sludge load of $35 \mathrm{~kg}$ of $B O D_{5} / \mathrm{day}$, the volume of water varied between 30 and $50 \mathrm{~m}^{3} / \mathrm{day}$.

3) A correct concentration of oxygen in the oxidation tanks and a sufficient flow of the return sludge. After studying the evolution of the microflora involved in the nitrogen cycle, of the different forms of nitrogen in the effuent and of the concentrations of dissolved oxygen obtained in the oxidation tanks, we were able to determine an optimum operating time for the compressor (the average temperature of the water : $\mathrm{I}_{7}^{\circ} \mathrm{C}$ ) of $65 \mathrm{p}$. 1 oo $i, e . \mathrm{I}_{5} .6 \mathrm{hours} / \mathrm{day}$.

We estimated the operating cost at $86 \mathrm{~F} /$ day. This is a high figure, but if we estimate the maximum possible total pollution given by swine only, it is comparable to already published costs on similar units : 33 If for I swine from weaning to slaughter. 